\title{
The global church and family planning: creative collaboration
}

Family planning is both a crucial issue for global health and a sometimes vexatious issue for many individual Christians and church institutions. Secular approaches to family planning, not infrequently, endorse abortion and sideline the sacramental and spiritual aspects of marriage. For these reasons the journal editors felt that a special issue devoted to family planning would be appropriate for a Christian journal devoted to global health. We invited submissions on the subject and were rewarded with an excellent variety of contributions. A print version of a portion of the issue will be available for the July 2017 conference of Christian Connections for International Health at John's Hopkins University in Baltimore. This editorial will highlight not only the family planning articles in that version, but additional submissions on other subjects received since our last issue.

Family planning has been promoted as part of a Christian global health agenda, as exemplified in a previous editorial by Mosley. ${ }^{1}$ Two case studies illustrate approaches to fostering family planning within this agenda. Docking, a nurse midwife from Australia, describes how her personal experience of being present at maternal deaths in Uganda moved her to create an interactive curriculum called Wise Choices for Life. This has a positive focus on God's design for true love, commitment, and faithfulness; she strongly advocates for an expanded role of the church in providing training on sexuality. Allison \& Basikoro describe why World Vision has refocused its work in family planning, now calling it Healthy Timing and Spacing of Pregnancy. The old focus on limiting population growth had failed to result in significant increases in contraceptive prevalence rates. The new focus on maternal and child health resonates better with people and faith leaders.
Two submissions describe how Christian health associations have facilitated the implementation of family planning methods in challenging circumstances. VanEnk and her colleagues describe how Catholic and Protestant health organizations were able to work together in East Africa to provide training, supervision, commodity availability, family planning promotion, data collection, and a supportive environment by being sensitive to cultural and doctrinal differences. Duah \& Yeboah report how in Ghana, 25 different denominations spanning a wide range of Christian beliefs provide family planning services tailored to the sociocultural and religious differences existing among them. The effort has seen a growth in the number of family planning acceptors.

Faith leaders play an important role in facilitating the acceptance of family planning measures, and Alikali assessed the attitudes and activities of pastors and faith leaders in eight provinces of Zimbabwe. He found that $44 \%$ of them actually counselled their members and $28 \%$ had had training in family planning.

Barriers exist to the implementation of family planning as we published in a recent study in Uganda by Shumba, et al. ${ }^{2}$ Three submissions described studies to surmount them. One barrier was when stockouts of relevant medicines and equipment occurred. Metzger \& Bormet surveyed 46 facilities in 13 African countries to discover the frequency of stockouts, the family planning products involved, and the types of supply chains that were relevant to the stockouts. Otchere and her colleagues initially used a health-promotion strategy called Social and Behavioral Change Communication in Uttar Pradesh, India that employed house-to-house visits and educational games initially. This was followed

July 2017. Christian Journal for Global Health, 4(2):1-2. 
in the second year by interface meetings between village leaders, mothers-in-law, and husbands to educate them regarding government entitlements, reinvigorating village sanitation and nutrition committees, and reopening dormant health centers. The authors provided details on the results of these efforts. Bhatta and colleagues leveraged an agricultural program for improving knowledge for family planning options, resulting in increased utilization in at least some areas of practice.

Meanwhile, several other articles on collaborations are included in this issue. Butcher \& Grills describe the impact of a community health worker training program in India. Mitchell \& Grills reports on a collaboration between Australian faith-based development organizations to deal with climate change-related health challenges and disasters in the Pacific island region, reasoning that crossdenominational efforts can be more effective influences in civil society. Supplementing this report is Pallant's review of Mitchell's excellent book Faith-based Development, showing how Christian organizations can better work in development using the resources of faith. Several editors attended a conference at Duke University Divinity School in May, Practice and Presence, which focused on Ignatian practice of meditation and imaginative

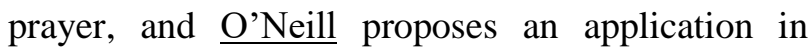
clinical and global health contexts.

The editors are grateful to have had the collaboration of Drs Michael J. Sleasman and Paige Comstock Cunningham from the Center for Bioethics and Human Dignity in the reviewing and editing of this issue, as well as Dr Douglas Huber and Mona Bormet from Christian Connections for Inter- national Health who catalyzed many operational studies. We are grateful to have received a grant from Advancing Partners and Communities from USAID for this issue. The interface between theology, ethics, and practice in the area of family planning requires thoughtful reflection and critique. In a guest editorial, Oas opines on how caution is necessary when Christian organizations undertake to partner "with institutions that promote an approach to family planning that is at odds with Christian values." A significant number of organizations active globally in family planning continue to advocate for abortion and are vocal in their opposition to provisions in US law that limit the abortion license. But abortion is not the only sticking point. Oas' thoughtful and provocative essay illustrates how terminology and concepts, including many used in the submissions outlined above, do not mean what they seem to mean. Often, behind their use is a frame of reference that is at odds with the Christian understanding of sexuality, marriage, and the family. Some readers may take issue with this frank, but penetrating analysis, which we believe gives them an opportunity to peruse, reflect, and respond. We welcome respectful comments and promise to reply.

\section{References}

1. Mosley WH. (2014). Family planning as a Christian global health agenda. Christan Journal for Global Health Nov 2014; 1(2):2-4. https://doi.org/10.15566/cjgh.v1i2.47

2. Shumba CS, et al. A qualitative study on provider perspectives on the barriers to contraceptive use in Kaliro and Iganga districts, Eastern Central Uganda. Christian Journal for Global Health, Nov 2016; 3(2):60-71. https://doi.org/10.15566/cjgh.v3i2.114.

www.cjgh.org

July 2017. Christian Journal for Global Health, 4(2):1-2. 